\title{
Pesquisa histórica e análise de conteúdo: pertinência e possibilidades
}

\section{NÚNCIA SANTORO DE CONSTANTINO*}

Resumo: Argumenta-se sobre possibilidades e adequação da metodologia de Análise de Conteúdo à pesquisa histórica. Para tanto, analisam-se aspectos teórico-metodológicos da História; aborda-se a diferença entre Análise de Conteúdo e Análise de Discurso; comentam-se as etapas para o desenvolvimento de $A C$, assim como as principais técnicas ao seu desenvolvimento. Conclui-se que é uma metodologia com amplas possibilidades de escolha, capaz de auxiliar no desenvolvimento das capacidades de inferir e de intuir, fundamentais à pesquisa histórica.

Abstract: The possibilities and adequation of the methodology of "content analysis" for the historical research are discussed. For such, theorical-methodological aspects of History are approached; the difference between "content analysis" and "speech analysis" is clarified; comments are made about the stages for the development of "CA", as well as the principal techniques for development. It follows that it is a methodology with wide possibilities of choise, capable of helping in the development of the capacities of deduction and intuition, fundamental for the historical research.

Palavras-chave: Pesquisa histórica. Metodologia de análise. Produção de inferências.

Key words: Historical research. Methodology of analysis. Production of inferences.

O momento é oportuno às ponderações que pretendo fazer, analisando as possibilidades da Análise de Conteúdo na pesquisa histórica, decorrentes sobretudo de fundamentos teóricos comuns. Emprego a expressão usada com maior freqüência, pois alguns autores, recentemente, passaram a substituí-la por Análise Textual Qualitativa.**

* Doutora em História Social; Docente da PUCRS.

** De grande valia ao presente trabalho foram as opiniões manifestadas por colegas e alunos, após leitura de texto preliminar. Agradeço especialmente a contribuição dos Professores Doutores Earle Macarthy Moreira, do Pós-Graduação em História PUCRS - e Roque Moraes, do Pós-Graduação em Educação - PUCRS; assim como aos alunos do seminário "Análise de Conteúdo e Documento Histórico", durante o primeiro semestre de 2001: Ângela Flach, Bernadete Schiavo Caprara, Carla Monteiro de Souza, Elaine de Vargas Sodré, Heliane de Souza Nunes, Nara Regina Nunes da Silva, Sandra Silveira, Silvana Corbellini, Susana Porcello Schilling, Vinicius R. Mayer e Zelinda Rosa Scotti.

Estudos Ibero-Americanos. PUCRS, v. XXVIII, n. 1, p. 183-194, junho 2002 
O momento é oportuno às ponderações, porque a História demonstra continuar sendo uma busca de verdades no passado, e assim, na historiografia , o pós-modernismo recua. Seus seguidores tentaram reduzir uma forma consolidada de conhecimento crítico aos estreitos limites daquilo que seria um discurso retórico ou estético. Não conseguiram tal redução da História.

Dentre a maioria dos historiadores contemporâneos, Ginzburg exemplifica uma sólida posição contrária aos sequazes do pós-modernismo, nos nove ensaios reunidos em livro.' Resenhei a obra que esclarece a oposição do autor. ${ }^{2}$ De sua crítica às "teorias da moda que tendem a dissipar os limites entre História e ficção", posso inferir que considera o relativismo relativo. ${ }^{3}$

Destacar Ginzburg também serve para lembrar que emprega de forma magistral a Análise de Discurso - $A D$, essencialmente adequada ao método indiciário e à micro-história. Obtém excepcionais resultados a partir da $A D$, graças aos seus amplos conhecimentos de filologia, característica marcante na tradição historiográfica italiana. Aproveito para definir Análise de Discurso, pretendendo distingui-la da Análise de Conteúdo - AC.

A Análise de Discurso destaca matérias semânticas,valorizando as condições de enunciação e dando maior atenção ao conteúdo latente. Com $A D$, deseja-se sobretudo saber como foi produzido o texto. A origem de AD é o ponto de vista das condições de produção do texto, conforme Orlandi. ${ }^{4}$ Assim, realizar tal forma de análise exige específicos conhecimentos teóricos, fundamentados no âmbito da lingüística ou da psicanálise, ou em ambos, como Lacan.

A versão mais desenvolvida e atual fundamenta-se em metodologia criada pelo filósofo Pêcheux, na década de 1960, articulando o Materialismo Histórico com a Lingüística e com a Teoria do Discurso. Adverte Pêcheux que a Teoria da Subjetividade permeia essas três regiões teóricas, com sua natureza psicanalítica, explicando o caráter recalcado na formação de significados. Dois princípios resumem os pressupostos da $A D$ : o sentido de uma palavra não existe em si mesmo, mas expressa posições ideológicas; toda a formação discursiva dissimula sua dependência das forma-

GINZBURG, Carlo. Occhiacci di legno: nove riflessione sulla distanza. Milão: Feltrinelli, 1998.

Estudos Ibero-Americanos, Porto Alegre, PUCRS, v. 26, n. 2, p. 175-186, dezembro 2000 .

Ginzburg, op. cit., p. 34.

ORLANDI, E. P. A linguagem e seu funcionamento. As formas do discurso. Campinas:

Pontes, 1987, p. 130-145. 
ções ideológicas. ${ }^{5}$ Orlandi define Análise de Discurso como proposta crítica para problematizar evidências, explicitando seu caráter ideológico e denunciando formas de dominação política. ${ }^{6} \mathrm{O}$ material sob análise precisa ser lido para apreensão do todo, sem nunca perder de vista as partes; compreende-se o todo a partir de determinadas questões e com orientação definida.

Há poucos historiadores habilitados ao emprego da Análise de Discurso. Exige vasta e forte base teórica, processada a partir de outras áreas de conhecimento que passam longe do currículo dos profissionais da História. Por outro lado, o uso de AC é limitado pela quantidade de material para análise, dadas as inúmeras operações classificatórias necessárias, simultaneamente semânticas, lógicas e sintáticas. Aspecto que também precisa ser considerado no uso de $A D$ refere-se aos riscos da rigidez ideológica, freqüentes na interpretação dos testemunhos à luz de teoria crítica. $\mathrm{O}$ historiador precisa separar a pergunta que faz ao passado da resposta que gostaria de obter.

Assim, o uso da Análise de Conteúdo apresenta-se como alternativa metodológica ao historiador. ${ }^{7}$ Desde que considere a História distanciada de verdades demonstráveis, verificáveis, invariáveis. Desde que admita a contingência não previsível e a interferência de observadores sobre os fenômenos observados. No século XXI e sem constrangimento, a História já está concebida como resultado de um esforço criador.

Historiadores sempre decidiram sobre suas fontes e analisaram textos. O passado foi sendo alcançado por traços que subsistiram, em maioria sutis. Adverte Marrou que, mesmo quando há textos, pode não haver documento. Para que um texto seja documento, intervém personalidade, formação técnica, talento e cultura do historiador. Acrescenta que a pesquisa, compreensão e exploração de documentos é a forma como o historiador constrói uma resposta à pergunta que formulou ao passado. ${ }^{8}$

\footnotetext{
PÊCHEUX, M. Semântica e discurso. Campinas: Ed. Unicamp, 1988, p. 160-162.

Orlandi, op. cit., p. 11-13.

Sobre Análise de Conteúdo, recomenda-se, além de Bardin: GRAWITZ, M. Méthodes en sciences sociales. Paris: Dalloz, 1986; MINAYO, Maria Cecília de Souza. O desafio do conhecimento: pesquisa qualitativa em saúde. Rio de Janeiro: Hucitec-Abrasco, 1998; MORAES, Roque. Análise de Conteúdo: limites e possibilidades. In: ENGERS, M. E. Paradigmas e metodologias de pesquisa em educação. Porto Alegre: EDIPUCRS, 1994; OLABUENAGA, J. I. R. \& ISPIZUA, M. A. La descodificacion de la vida cotidiana: metodos de investigación qualitativa. Bilbao: Universidad de Deusto, 1989; TRIVINŌS, A. N. S. Introdução à pesquisa em ciências sociais: a pesquisa qualitativa em educação. São Paulo: Ática, 1987.
}

8 MARROU, Henri-Irénée. Sobre o conhecimento histórico. Rio de Janeiro: Zahar, 1978, p. 45-59, 119. 
De sua parte, Elton enfatiza a necessidade de libertar a História "[...] da mistura de lingüística, de crítica textual [...]" ou mesmo da "Psicologia, com seu relativismo nominalista". Insurge-se contra os excessos do narrativismo e contra os exageros teóricos. Recomenda, acima de tudo, uma acurada leitura dos traços de acontecimentos e de experiências do passado. "A correta leitura dos testemunhos históricos [...]", escreve "[...] exige pelo menos um certo tirocínio, uma capacidade profissional estudada e apreendida". "

Essa capacidade pode ser exercitada através da Análise de Conteúdo. Já é tempo de dizer que a expressão Análise de Conteúdo designa conjunto de técnicas cuja aplicação, através de procedimentos sistemáticos, visa produzir inferências. ${ }^{10}$ São técnicas para ler e interpretar o conteúdo de qualquer espécie de documento e, mais concretamente, de toda a espécie de documento escrito. ${ }^{11}$

Aproveito para repetir aquilo que é quase tão velho como a Sé de Braga: vestígios só adquirem sentido quando relacionados a um problema fundamental colocado ao passado. Outros aspectos tão antigos como a referida Sé precisarão ser lembrados.

Aprendizes do ofício sempre ouviram (e continuam ouvindo) falar da Heurística, assim como das Ciências Auxiliares da História. Menções à paleografia, epigrafia, cronologia, estatística ou filologia são feitas nas primeiras disciplinas de um curso universitário de História. Disciplinas do âmbito da Geografia são obrigações curriculares, leituras em línguas estrangeiras fazem parte do dia-a-dia do estudante.

Qualquer manual de Introdução ao Estudo da História apresenta, como parte do método historiográfico, as chamadas operações analítico-sintéticas, que se referem à crítica externa. É bem verdade que foram abandonadas as subdivisões, catalogações ou rotulações freneticamente atribuídas às fontes, naquela antiga e compulsiva ânsia de denominar, de esquematizar, como forma de legitimar uma ciência.

Fica-se hoje na análise e na síntese, entendidas em primeiro lugar como processos ou conjunto de operações. A análise decide sobre a autoridade das fontes, sobre sua credibilidade e força de argumentação. A síntese conduz à produção histórica propriamente dita.

9. ELTON, Geoffrey. Ritorno alla storia. Milão: Il Saggiatore, 1994, p. 66-68.

10 BARDIN, Laurence. Análise de conteúdo. Lisboa: Edições 70, s.d., p. 42.

11 OLABUENAGA, Jose I. Ruiz \& ISPIZUA, Maria Antonia. La descodificación de la vida cotidiana: metodos de investigaçión cualitativa. Bilbao: Universidad de Deusto, 1989, p. 182. 
Mas o mencionado manual dedicará pelo menos um capítulo à hermenêutica, cuja definição o estudante certamente vai decorar, cercando com palavras um terreno ainda vazio de idéias. Repetirá muitas vezes que o historiador, praticando a hermenêutica, interpretará o sentido das palavras. Não se trata mais de saber sobre a autenticidade dos selos, das moedas, do papel, ou da validade de um sinal gráfico. Trata-se agora de saber o que disse o autor, qual o sentido literal de sua comunicação, o que desejou efetivamente dizer, em que contexto escreveu e para quem o fez.

Além da hermenêutica, outra espécie de operação mental de cunho crítico foi ensinada como "crítica de objetividade", subdividida em crítica de competência, de sinceridade, de controle. Em outras palavras, diante de um texto, é preciso refletir se o autor podia conhecer a verdade; se possuía motivos para mentir; se sua narrativa resiste ao confronto com outras fontes.

De outra parte, até bem pouco tempo, o dilema teóricometodológico dos historiadores praticamente restringia-se aos pressupostos da esfera sociológica e da esfera antropológica. Hoje é reconhecida a importância de outras e diversificadas aproximações interdisciplinares. Considerem-se os muitos e recentes avanços em específicas áreas do conhecimento, como teoria da comunicação ou teoria literária, cuja menção é pertinente ao assunto aqui desenvolvido. Ademais, enfrenta-se o problema dos limites interdisciplinares indefinidos, de fronteiras intelectuais confusas. Referências a Foucault, Bakhtin, Ricoeur ou Bourdieu aparecem na leitura cotidiana dos historiadores. São referências instigantes, desafiadoras, que não podem ser ignoradas e que exigem elaboradas reflexões.

É bem lembrado por Cardoso e Vainfas, que Lucien Febvre já havia percebido as possibilidades da análise de estrutura formal de um texto, ou seja, do vocabulário, enunciados, tempos verbais, etc., quando realizou o estudo sobre Rabelais, publicado em 1942. O historiador francês, então, já sublinhava a perspectiva da interdisciplinaridade, que caracterizaria a produção da História nos anos subseqüentes. ${ }^{12}$

Tanto Febvre quanto Bloch desejaram alcançar outras áreas do conhecimento; ambos eram interessados em lingüística e nos estudos antropológicos de Lévy-Bruhl. Mas, enquanto Febre concentrava-se na geografia e na psicologia, Bloch aproximava-se da sociologia de Durkheim e dos estudos de Halbwachs sobre a estru-

12 CARDOSO, Ciro Flamarion \& Vainfas, Ronaldo. Domínios da História: ensaios de teoria e metodologia. Rio de Janeiro: Campus, 1997, p. 377. 
tura social da memória. Com o assassinato de Bloch pelos nazistas, em 1944, Febvre lidera a historiografia francesa, assegurando a cooperação interdisciplinar que conferiu à História uma posição hegemônica entre as Ciências Sociais, como escreve Burke. ${ }^{13}$

Tornou-se característica dos historiadores contemporâneos uma atitude que se traduz na busca de correlações, no estreitamento de acordos e de trocas com outras áreas do conhecimento. Em outras palavras, na busca de novas chaves que permitam interpretar. Então, um dos aspectos a destacar é a questão da interdisciplinaridade na produção histórica.

Análise de Conteúdo pode vir a ser, para o historiador, um eficiente conjunto de técnicas de pesquisa, em abordagem interdisciplinar, muito desenvolvido pelos recentes avanços no campo da comunicação. Tem como primeiro objetivo buscar sentido ou sentidos no texto e fundamenta-se nos pressupostos da concepção dinâmica da linguagem, entendida como construção real de cada sociedade e como expressão da existência humana; elaborando e desenvolvendo representações, em todos os momentos históricos. ${ }^{14}$

Produzir inferência ou desvelar significados é razão de ser da $A C$. Faz-se inferência, por exemplo, ao compatibilizar um conteúdo lido com alguma corrente teórica. Faz-se inferência a partir dos elementos básicos de um texto. Infere-se ao tentar saber quem é o emissor, quais suas filiações teórico-ideológicas, quais suas concepções de mundo, seus interesses de classe ou de categoria social, quais os traços psicológicos que evidencia, quais as suas motivações ou expectativas. Infere-se ao indagar sobre características do próprio texto, tais como: por que foi produzido, para quem foi enviado, qual o efeito causado por ocasião da publicação?

Marc Bloch continua sendo lembrado. Escreveu: "...aquilo que o texto expressamente nos diz deixou de ser o objetivo preferido da nossa atenção", para sublinhar que o maior interesse deveria ser o que o texto nos dá a entender, sem ter intenção de fazê-lo. ${ }^{15}$

Análise de Conteúdo é aquilo que historiadores sempre precisaram fazer, mesmo muito antes de que surgisse a expressão grifada, nos Estados Unidos, durante a Primeira Guerra Mundial. Manifestava-se então a antológica compulsão por números e por técnicas estatísticas, elementos decantados como legitimadores, até mesmo sinônimos do pretendido rigor científico. 
Uma atividade inicial fora a análise do material de propaganda veiculado pela imprensa, desenvolvida no departamento de Jornalismo da Universidade de Colúmbia. Na década de 1940 passara a ser a análise estatística de valores, fins, normas, objetivos e símbolos, realizada a partir dos departamentos de Ciências Políticas, envolvendo pesquisadores de outras áreas, como sociólogos e psicólogos.

O debate recrudesce nos anos sessenta e, sob o ponto de vista metodológico, a discussão polariza-se entre as abordagens quantitativa e qualitativa, a exemplo do que sucedia em outras áreas do conhecimento. A primeira aprimora-se buscando sofisticadas medidas para compreender significações. Já os adeptos das técnicas qualitativas, segundo Minayo, contestam a eficiência das minúcias da análise de freqüência, como critérios de objetividade e de cientificidade, pretendendo ir além da mera descrição dos conteúdos manifestos em mensagens. Buscam, portanto, a inferência, ou a interpretação mais profunda. ${ }^{16} \mathrm{Na}$ análise quantitativa, serve a frequêencia com que surgem certas características do conteúdo do texto. $\mathrm{Na}$ abordagem qualitativa, a presença ou ausência de característica ou características é o que se leva em consideração.

Acirrada discussão metodológica com as mesmas características permeou o pensamento dos historiadores nas últimas décadas. Se nos anos cinqüenta e sessenta a maioria dos historiadores empregou métodos quantitativos, concentrando a análise sobre tendências gerais verificadas em grandes grupos humanos, nos anos setenta alguns estudiosos passaram do telescópio ao microscópio, na conhecida metáfora de Peter Burke. Destacam-se nesta abordagem as famosas publicações de Le Roy Ladurie e Carlo Ginzburg.

Ginzburg desenvolve os fundamentos do método indiciário, demonstrando sintomas ou indícios que funcionam como chaves para o conhecimento de realidades; minúsculas partes singulares tradicionalmente menosprezadas por predomínio de hábitos ou reflexos condicionados, enfim, por predomínio do inconsciente."

Modernas tendências historiográficas esquecem as generalizações, aceitam verdades prováveis e admitem o conhecimento histórico a partir de avaliações em termos de propósitos humanos. Em trabalho recente, procurei destacar a atualidade de Vico,

16 Minayo, op. cit., p. 202-203.

Ginzburg, op. cit. 
refutando a fórmula cartesiana da evidência quando se trata do passado. No mesmo ensaio, sublinho a importância de Dilthey para o desenvolvimento da abordagem qualitativa, ao afirmar que a Sociologia de Comte ou a de Spencer, demasiadamente genéricas, não davam conta da unicidade dos indivíduos e dos eventos. ${ }^{18}$

No âmbito da Análise de Conteúdo, muitas técnicas vêm sendo aperfeiçoadas, compatíveis às atuais tendências historiográficas e diferentes capacidades evidenciadas entre historiadores. É de fundamental importância o reconhecimento da possibilidade de ler em duas dimensões: no sentido manifesto ou ao pé da letra; como leitura soterrada, buscando o sentido latente.

Quanto ao tratamento de dados, há alguma discussão entre aqueles que preconizam tratamento estatístico e outros que só admitem AC como leitura densa de texto aparentemente inexpressivo. Uma terceira via é apontada pelo bom senso: sejam utilizados procedimentos ou técnicas capazes de auxiliar na resolução dos específicos problemas propostos.

Abordando possibilidades e limites de $A C$, Moraes enfatiza que são determinados pelo paradigma do pesquisador. A escolha de procedimentos ou técnicas a serem empregados depende essencialmente dos interesses do pesquisador e dos objetivos da pesquisa. Demonstra o autor que a técnica não estabelece limites, mas é o pesquisador que delimita a mesma, em função dos fundamentos que o orientam. Reconhece que "[...] essa metodologia é extremamente versátil e adaptável". ${ }^{19}$

$A C$ representa um esforço teórico para desenvolvimento de técnicas, algumas delas até mesmo contraditórias, como registra Minayo, para "[...] ultrapassar o nível do senso comum e do subjetivismo na interpretação e alcançar uma vigilância crítica frente à comunicação de documentos, textos literários, biografias, entrevistas ou observação" ${ }^{20}$ A conhecida autora, professora da escola Nacional de Saúde Pública, com inúmeras publicações no âmbito da antropologia e do sanitarismo, parece estar falando especialmente para historiadores.

Minayo sublinha que, para atingir os significados latentes, além dos manifestos, várias técnicas têm sido desenvolvidas. Enu-

CONSTANTINO, Nuncia Santoro de. Sobre a Atualidade de Vico. Histórica. Revista da Associação dos Pós-Graduandos em História - PUCRS. Porto Alegre, n. 4, 2000.

19 MORAES, Roque. Análise de Conteúdos: possibilidades e limites. In: ENGERS, Maria Emillia A. Paradigmas e metodologias de pesquisa em educação: notas para reflexão. Porto Alegre: EDIPUCRS, 1994, p. 108-109.

20 Minayo, op. cit., p. 203. 
mera e explica cinco dessas técnicas, seguindo a exposição de Bardin. ${ }^{21}$ Assim, cita a Análise de Expressão que trabalha com indicadores lexicais, como estilo, para atingir a inferência. Análise das Relações verifica as relações que os vários elementos mantém entre si. A Análise de Avaliação ou Representacional pretende medir as atitudes do emissor em relação aos objetos de que fala. Análise de Enunciação trabalha com as condições de produção da palavra. Análise Temática busca a descoberta dos núcleos de sentido que compõem uma comunicação. Bardin, entretanto, coloca como sexta possibilidade a chamada análise automática do discurso, cujo objetivo é buscar inferências a partir dos efeitos de superfície, reveladores dos processos de produção. ${ }^{22}$

Toda $A C$ inicia por um conjunto de documentos - o corpus da análise, resultado de rigorosa seleção. Tratando-se de História, a organização do mesmo é sempre uma prática.

Textos, a princípio, não podem ser considerados corpus, como esclarece Barrera. Pois esses são constituídos por documentos que, por sua vez, assim ficam considerados quando ensejam intuições ao historiador. Sublinha o autor "[...] que não pode haver saber histórico se não foi estabelecido previamente um corpus documental". Denomina "sensibilidade histórica" à capacidade de obter intuições, "que não é inata, mas adquirida socialmente". ${ }^{23}$

Portanto, a intuição do historiador faz-se presente desde o início do processo de reconstrução histórica, como capacidade de perceber, discernir, apreender de imediato um objeto de sua realidade. É capacidade a ser desenvolvida, exercitada.

Organizado o corpus, a partir de produções textuais, inicia-se a análise propriamente dita, cujo primeiro passo é a desconstrução. Os textos serão desmontados em seus elementos constituintes, denominados unidades de análise ou unidades de registro. Tal fragmentação em unidades maiores ou menores rompe uma ordem pré-existente e depende da subjetividade do pesquisador, dos seus propósitos, assim como a definição das mesmas unidades.

O processo de desconstrução, por si só, possibilita uma leitura bem diferente daquela inicial. Trata-se de alcançar um metatexto, que expressa significados mais profundos, em diferentes perspectivas, de acordo com as hipóteses e com os objetivos da investigação, assim como depende de seus fundamentos teóricos.

Ibid., p. 204-208.

Bardin, op. cit., p. 155-222.

23 BARRERA, José C. Bermejo. Fundamentación lógica de la História. Madri: Akal, 1991, p. 20. 
A etapa seguinte da análise refere-se ao processo de categorização. Categorias são definidas, como conjuntos de unidades de análise. Um conjunto de categorias é resultado da fundamentação teórica do projeto, refletindo seu nível de abstração. Em outras palavras, toda categorização pressupõe um referencial teórico.

Categorias podem ser construídas do geral para o particular, a priori. Ou pode-se usar predominantemente o método indutivo, construindo categorias a partir do próprio corpus. Por constante comparação, organizam-se conjuntos de elementos semelhantes.

Moraes afirma poder descrever um terceiro método - o método intuitivo. Escreve o autor: "Chegar a um conjunto de categorias por meio da intuição exige integrar-se num processo de autoorganização em que, a partir de um conjunto complexo de elementos de partida, emerge uma nova ordem". ${ }^{24}$

Há duas propriedades exigidas às categorias: pertinência em relação aos objetivos e homogeneidade, isto é, sejam as categorias construídas a partir de um certo princípio.

Uma última etapa da análise refere-se à construção de um metatexto. Esta etapa exige esforço para expressar, inclusive, as intuições do pesquisador. Não pode limitar-se à descrição, mas precisa atingir níveis de inferência e de interpretação. Devem ser comunicadas as novas compreensões, explicitadas as novas descobertas emergentes da análise, tornados compreensíveis os fenômenos ou processos investigados.

Escreveu Bloch que, "[...] como todo o sábio, o historiador escolhe e aparta. Em suma, analisa". Referenciou que o historiador ordena os fenômenos humanos por cadeias de fenômenos semelhantes, registrando que classificá-los é o mesmo que desnudar linhas de força com fundamental eficácia. Disse que "[...] o trabalho de recomposição só pode vir depois da análise, pois é prolongamento da mesma". Adverte que toda análise exige uma linguagem apropriada, "como utensílio capaz de desenhar com precisão o contorno dos fatos [...] uma linguagem sem flutuações nem equívocos". ${ }^{25}$

Ao historiador é corriqueira a palavra síntese. Entende-se síntese como recomposição, como reconstrução, quando elementos do conhecimento são organizados assumindo configuração nova, original.

\footnotetext{
24 MORAES, Roque. Uma Tempestade de Luz: a compreensão possibilitada pela análise textual qualitativa. Porto Alegre: PUCRS, Pós-Graduação em Educação, 2000 (mimeo).

25 Bloch, op. cit., p. 126-128, 135-136.
} 
A pesquisa histórica deve resultar em texto, seja artigo, dissertação ou livro. Não basta um trabalho analítico, às vezes incluindo cálculos sofisticados para interpretação de dados; não bastam conhecimentos teórico-metodológicos, construção de conceitos, tipologias, modelos ou hipóteses, para serem utilizados como instrumentos heurísticos. É preciso comunicar em texto. É preciso escrever e escrever bem, dando conta da relação entre a pesquisa histórica realizada e a expressão escrita. Historiadores não comunicam resultados com símbolos dispostos em equação. Historiadores precisam narrar.

É o historiador quem escreve, pois pesquisa e expressão se interpenetram na prática. Procurando a expressão sabe-se que o conhecimento avança. A redação revela lacunas, enseja forma às verdades. Selecionando, simplificando e organizando, o historiador compõe a narrativa, a verdade no passado assume uma forma, respondendo indagações que refletem necessidades captadas no presente.

Desenvolvendo as últimas considerações, destacam-se aspectos do pensamento de Bourdieu. O sociólogo francês assinala que a formação do historiador ocorre, em grande parte, de maneira inteiramente prática, como os próprios historiadores freqüentemente admitem. Esclarecendo sobre a construção do objeto de pesquisa, adverte que a mesma não se verifica a partir de um ato teórico inaugural, mas é trabalho de grande fôlego, que se realiza pouco a pouco, com sucessivos retoques. Construir esse objeto supõe que se tenha postura ativa e sistemática diante dos fatos, capaz de estabelecer um sistema coerente de relações, pois o raciocínio analógico é excelente ferramenta à construção. Postula contra "hábitos do pensamento" quando afirma que construir um objeto é sobretudo romper com os lugares comuns, pois o pré-construído está em toda a parte. Essa ruptura, para o autor, é a produção de um novo olhar. ${ }^{26}$

São aspectos fundamentais, mas podem ser considerados bem mais velhos do que a Sé de Braga. O Imperador Marco Aurélio nas suas Máximas, como lembra Ginzburg, recomendava que as representações fossem canceladas para que houvesse a melhor percepção das coisas; que se repartisse em elementos aquilo que fosse importante, identificando as partes singulares e aprendendo a guardar distância, em atitude de estranhamento ao conhecido, ao que já está dito. ${ }^{27}$

BOURDIEU, Pierre. O poder simbólico. Lisboa: Difel, s.d. Capítulo II.

Ginzburg, op cit., cap. I. 
Se ao leitor fosse solicitada $A C$ do texto cuja leitura finaliza, penso que na desconstrução faria da recorrente expressão Sé de Braga uma unidade, para depois categorizar. O dito popular pode representar fonte de inferências. A autora poderá estar tentando amenizar um texto árido, tentando deixar melhor impressão derradeira. Ou ainda está deixando transparecer o desejo de conhecer a Sé de Braga, tão magistralmente descrita por Saramago, em Viagem a Portugal, na sua multiplicidade de estilos que atestam antiguidade, esclarecendo o significado do dito popular.

Registrado o meta-texto a partir de inferências, conclui-se que Análise de Conteúdo é metodologia que pode ser utilizada através de várias técnicas, ou da livre combinação dessas, em perspectiva interdisciplinar. Sendo amplas as possibilidades de escolha, tornam-se técnicas viáveis com relação a diversos propósitos, ou a diferentes níveis e tipos de formação dos historiadores. $A C$ propõe sistematicamente a realização de operações analítico-sintéticas, através de procedimentos que auxiliam no desenvolvimento das capacidades de intuir e de inferir.

Uma última inferência poderá ser feita por historiadores: ovo de Colombo. 